\title{
An Introduction of New Features for Conventional and Hybrid GSHP Simulations in eQUEST 3.7
}

Shaojie Wang ${ }^{a, *}$

${ }^{a}$ ClimateMaster, 7300 SW $44^{\text {th }}$ Street, Oklahoma City, OK 73179

Xiaobing Liu ${ }^{b}$

${ }^{b}$ Oak Ridge National Lab

Steven Gates ${ }^{c}$

${ }^{c}$ James Hirsch \& Associates

\begin{abstract}
Three new enhancements, newly implemented into eQUEST 3.7 are presented here. These enhancements include: (1) Simulation of ground coupled water-to-water heat pump systems; (2) Improved multi-year simulations for conventional and hybrid ground source heat pump (GSHP) systems; (3) Model of hybrid GSHP (HGSHP) system configurations. The capabilities of each new feature are outlined and some details of the implementation or simulation techniques of each feature area are briefly discussed. Also, the new wizard features are introduced to show how to build the models through the wizard interfaces.
\end{abstract}

Keywords: hybrid ground source heat pump, multi-year simulation, water-to-water heat pump

*Corresponding author. Tel.: +1 9722070380.

E-mail address: wsjsxn@gmail.com (S. Wang). 


\section{Introduction}

eQUEST is a widely-accepted building and HVAC system energy analysis tool that is powered with the latest implementation of the DOE-2.3 building energy simulation program. Approximately 20 years ago, the DOE-2 simulation engine was enhanced to simulate conventional ground source heat pump systems. The systems supported consisted of:

- Water-to-air heat pump units

- A water loop distribution system consisting of piping, pumps, and controls

- Horizontal or vertical ground loop heat exchangers (GLHX) to accept or reject the heat imbalance that arises between those heat pump units operating in the heating mode vs. those operating in the cooling mode

- As an alternative to a ground loop heat exchanger, the water loop could be coupled to a lake or well

The original implementation of the GLHX simulation capability (horizontal trenches and vertical well fields) was based on algorithms developed by R. Merriam of Arthur D. Little, and ported into DOE-2 by James Hirsch and Steven Gates in 1995. In 2006, the vertical well field model was replaced with a more accurate model based on g-functions. As shown Equation 1, the g-function formulation is based upon work by Claesson et al. [1][2], Eskilson et al.[3], Hellstrom et al. [4] at the University of Lund in Sweden, and Yavuzturk et al. [5] at Oklahoma State University. Their algorithm was enhanced and adapted to DOE-2 by Xiaobing Liu of ClimateMaster [6].

$g\left(\frac{t}{t_{s}}, \frac{r_{b}}{H}, \frac{B}{H}\right)=\frac{2 \pi k_{s}}{\bar{Q}}\left(\overline{T_{f}}-\bar{Q} R_{e f f}-T_{g}\right)$

Where:

$\overline{T_{f}}:$ mean fluid temperature,

$T_{g}:$ undisturbed ground temperature, 
$\bar{Q}$ : total heat extraction rate per borehole length,

$k_{S}$ : ground thermal conductivity,

g: g-function,

$t / t_{S}:$ non-dimensional time, with $t_{S}=H^{2} / 9 \alpha s$ the characteristic time of the bore field, $\alpha$ : the ground thermal diffusivity,

$r_{b} / H$ : borehole radius to length ratio

$B / H$ : borehole spacing to length ratio.

Uniform borehole wall temperature

$R_{e f f}=R_{b}+\frac{1}{3 R_{12}}\left(\frac{H}{C_{f} V_{f}}\right)^{2}+\frac{1}{12 R_{b}}\left(\frac{H}{C_{f} V_{f}}\right)^{2}$

Uniform heat flux on borehole wall

$R_{e f f}=R_{b}+\frac{1}{3 R_{a}}\left(\frac{H}{C_{f} V_{f}}\right)^{2}$

While powerful, the DOE-2 GLHX algorithms were missing several features that limited their usefulness:

- Simulation of water-to-water heat pumps - While water-to-air heat pumps (zonal DX units coupled to a water loop) are the most common configuration, many systems use water-to-water heat pumps supplying 2-pipe fan coils. In DOE-2, water-to-water heat pumps existed, but were restricted to lakes or wells; coupling to ground loop heat exchangers was not supported.

- Multi-year simulation of GLHX systems - While DOE-2 could simulate a building and its HVAC systems on an hourly basis for an entire year, it was not capable of multi-year simulations. However, the thermal performance of a GLHX can vary drastically over the course of its lifetime, as a net annual heating/cooling imbalance may build up over the years. DOE-2 
incorporated an approximate method to account for the history of the prior years' thermal imbalances, but the approach used had major shortcomings.

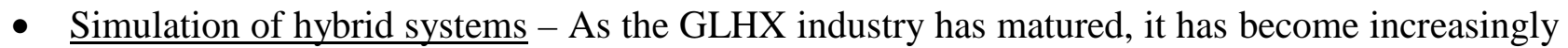
evident that many projects have a net annual heating/cooling imbalance sufficiently large that it can severely impact GLHX performance over its lifetime. Either the GLHX must be sized considerably larger (possibly at considerable expense), or supplemental cooling towers and/or boilers must be incorporated to mitigate the net annual thermal imbalance. The use of supplemental equipment in conjunction with a GLHX is termed a hybrid ground source heat pump (HGSHP) system. DOE-2 did not have the capability to simulate HGSHP systems.

Through this DOE-sponsored project, ClimateMaster was the lead for a group of world reknowned experts including ClimateMaster, James J. Hirsch and Associates, and Oak Ridge National Laboratory. Their goal was to enhance the simulation capacity of eQUEST and make it a more powerful tool for performing energy analysis and optimizing the design of ground source heat pump (GSHP) systems. With the addition of the proposed new capabilities, eQUEST becomes an integrated modeling tool that enables prospective GSHP system customers to analyze the cost and performance of a variety of GSHP system applications. As such, it should serve as a powerful tool for use in purchasing and design decisions.

\section{Summary of implemented modeling enhancements}

This section briefly describes three new enhancements to existing models that were implemented in eQUEST 3.7[7]. 


\subsection{Improved multi-year simulations for conventional and hybrid GSHP systems}

The performance of ground-loop heat exchangers is affected by the loading history of the ground heat exchanger, especially when there is an imbalance between the annual heat rejection to the ground and the heat extraction from the ground. Previously, the loading history of a GLHX was approximated in eQUEST/DOE-2.2 with a simplified algorithm, which estimated an annual load profile using the estimated peak winter heating load vs. the peak summer cooling load, and assuming a sinusoidal variation between the two peaks to develop the yearly profile.

In reality, annual heating and cooling load profiles are usually not proportionate to the peak heating and cooling loads. For office buildings, annual heating loads are typically over-estimated using this technique, and act to reduce the thermal imbalance of a well field serving a cooling-dominated building. Therefore, two versions of a multi-year history simulation were implemented including all-years and sample-years.

For all-years simulation, each successive year in the history is simulated using the actual loading history calculated in the simulation of the previous years. This approach allows the first-year performance to be distinguished from later years when the ground has progressively become more saturated with the annual heating/cooling load imbalance. In this approach, if the actual simulation is for the 30th year of operation, then all 29 previous years of operation are also simulated as shown in Equation 4; resulting in a potentially long run period.

$\bar{Q}_{\text {history }}=\frac{\sum_{i=1}^{n} Q_{i}}{n}$

Where:

$n:$ years of operation, 
$Q_{i}:$ net thermal load on the ground loop in year $\mathrm{i}$

Instead of simulating every year in the history, only the sample years corresponding to the Fibonacci sequence $\{1,2,3,5,8,13,21, \ldots\}$ are simulated. Where years are skipped, the ground history of the next simulated year is weighted by the number of years skipped. As depicted in Equation 5, this method recognizes that the ground temperature changes the most rapidly during the early years, and changes more slowly in later years as the ground approaches thermal equilibrium.

$\bar{Q}_{\text {history }}=\frac{\sum_{i=1}^{k} Q_{i}+(n-k) Q_{n+1}}{n}$

Where:

$k$ : sample years of operation,

$n$ : years of operation,

$Q_{i}:$ net thermal load on the ground loop in year i

The advantage of Option (a) is that it fully captures the variation in well field temperature over successive years, and is the most accurate. Option (b) may be somewhat less accurate, but can result in significantly faster run times. The temperature rise is presented in Equation 6. Tests comparing Option (a) to Option (b) show very little difference between the two methods. For histories of 20 to 30 years, results showed the variation in well field temperature to be typically less than $1^{\circ} \mathrm{F}$. Both modes of generating the history are supported, with the Fibonacci sequence being the default.

$d T_{\text {history }}=\frac{\bar{Q}_{\text {history }}}{2 \pi k_{s}} \cdot g\left(\frac{t}{t_{s}}, \frac{r_{b}}{H}, \frac{B}{H}\right)$ 
The upgraded program performs year-by-year simulations with loading history of GLHX in previous years. As shown in Fig. 1, the annual load of GLHX decreases over time, especially in the first few years when the GLHX is becoming saturated and the cooling tower picks up more loads. The year-byyear simulation helps provides a more accurate prediction of the ground loop temperature, and thus enables more accurate prediction of the performance of the GSHP system. In addition, a new load aggregation algorithm [7] has been implemented to accelerate the computation speed of the multi-year simulation. More detailed reports were added to display the output of simulated performance of conventional and hybrid GSHP systems.

Fig. 1 Heat rejection loads for hybrid GSHP system

\subsection{Model of hybrid distributed GSHP system}

As shown in Fig. 2, a cooling tower and/or a boiler can be placed in series and downstream of GLHXs. Various cooling towers can be selected, including fluid cooler, dry cooler, or open tower, attached to the same water loop as the GLHX. A water pump is attached to the water loop and circulates the water between the GLHX, fluid cooler, and the condenser.

This model has various supplemental device control strategies [8] to maintain a fixed or variable

maximum entering fluid temperature (EFT) to the heat pump. In the cooling mode, these include fixed setpoint, outside air reset, load reset, schedule, and wetbulb reset.

The fixed temperature control specifies the loop supply temperature at a fixed value. The OA-RESET specifies that the loop supply temperature is reset on outdoor air according to the COOL-RESET-SCH. 
LOAD-RESET specifies that the loop supply temperature is reset so that the valve of the worst-case coil is fully open. LOAD-RESET is applicable to the heat-rejection side of a WLHP loop. It does not apply, however, to the heating setpoint of a WLHP loop.

The fluid cooler temperature floats with the load and wet-bulb temperature. This mode maximizes the efficiency of the primary equipment and minimizes the loop's thermal losses (but at the expense of pumping energy in a variable-flow loop). The loop supply temperature is controlled to a schedule specified by the COOL-SETPT-SCH.

WETBULB-RESET specifies that the loop temperature cooling setpoint is reset according to the outdoor wetbulb temperature, plus an offset. The offset may be either fixed, or may vary with the wetbulb. The heating loop setpoint control sequence has the same options except WETBULB-RESET.

The GLHX and the supplemental heating/cooling equipment are sized based on the downstream split ratio, which determines the designed heating or cooling load to be picked up by the supplementary equipment. The supplementary equipment is always assumed to be bypassed when inactive. The GLHX will be preferentially loaded over the supplemental devices. However, if the GLHX is counterproductive (i.e., warming the water when heat pumps are in cooling mode), and a supplemental device is also enabled, then the GLHX will be bypassed (to save pump energy) and the supplemental device used exclusively.

Fig. 2 Schematic of hybrid GSHP system

Table 1 Water-Air heat pump capacity and EIR performance curves

The performance curves listed above in Table 1 are used to calculate the correction factors based on 
various entering air and water temperatures. The hourly heating /cooling capacities and power consumptions are determined in Equations $(7) \sim(10) . Q_{c_{-} c a p}$ and $Q_{h_{-} c a p}$ are the hourly cooling and heating capacities. $Q_{c_{-} \text {cap_rated }}$ and $Q_{h_{-} \text {cap_rated }}$ are the cooling capacities at the rated conditions. $Q_{c_{-} c a p_{-} C F}(E W B T, E F T), E I R_{h_{-} C F}(E D B T, E F T), Q_{h_{-} c a p_{-} C F}(E D B T, E F T)$, and $E I R_{h_{-} C F}(E D B T, E F T)$ represent the capacity and EIR correction factors in the cooling and heating modes.

Hourly cooling capacity:

$Q_{c_{-} c a p}=Q_{c_{-} \text {cap_rated }} \times Q_{c_{-} c a p_{-} C F}(E W B T, E F T)$

Hourly cooling power consumption:

$P_{c}=Q_{c_{-} \text {cap }} \times E I R_{c_{-} \text {rated }} \times E I R_{C_{-} C F}(E W B T, E F T)$

Hourly heating capacity:

$Q_{h_{-} c a p}=Q_{h_{-} \text {cap_rated }} \times Q_{h_{-} \text {cap_cF }}(E D B T, E F T)$

Hourly heating power consumption:

$P_{h}=Q_{h_{-} \text {cap }} \times E I R_{h_{-} \text {rated }} \times E I R_{h_{-} C F}(E D B T, E F T)$

\subsection{Model of water-to-water heat pump system}

In addition to modeling the distributed GSHP system, the upgraded program can also model central GSHP systems as illustrated in Fig. 3. This system uses a central water-to-water heat pump (W-W HP) to provide hot or chilled water to the 2-pipe fan coil system. This model allows a central W-W HP or heat pump chiller to be coupled with horizontal or vertical GLHXs. It uses: (1) an improved W-W HP model to account for the impact of varying condenser and/or evaporator water flow rates on capacity and efficiency and (2) an enhanced fan coil algorithm to model better the relatively low heating supply temperature provided by a W-W HP. 
Fig. 3 Schematic of Central GSHP System

The upgraded program is a fully-integrated building and GSHP/HGSHP system simulation, and is computationally effective. It performs real, multi-year simulations to account for yearly variations of GLHX loads. It uses pre-defined models with many options (easy-to-use) and provides comprehensive and dedicated reports for evaluating the design and performance of GSHP/HGSHP systems.

As addressed in Table 2, the correction factors are the functions of entering fluid temperature, and chilled/hot water supply temperatures.

Table 2 Water-to-Water heat pump capacity and EIR performance curves

Similar to water-to-air heat pump, the hourly heating /cooling capacities and power consumptions are calculated based on Equation (11) (14).

Hourly cooling capacity:

$Q_{c_{-} \text {cap }}=Q_{c_{-} \text {cap_rated }} \times Q_{c_{-} \text {cap_c } C F}(C H W, E F T)$

Hourly cooling power consumption:

$P_{c}=Q_{c_{-} \text {cap }} \times E I R_{c_{-} \text {rated }} \times E I R_{C_{-} C F}(C H W, E F T)$

Hourly heating capacity:

$Q_{h_{-} c a p}=Q_{h_{-} c a p \_r a t e d} \times Q_{h_{-} c a p_{-} C F}(H W, E F T)$

Hourly heating power consumption:

$P_{h}=Q_{h_{-} c a p} \times E I R_{h_{-} \text {rated }} \times E I R_{h_{-} C F}(H W, E F T)$

However, the current version also has some limitations. First, it cannot directly simulate dedicated borehole thermal storage (e.g., cool ground during the night with a cooling tower). Second, it cannot 
directly simulate HGSHP systems where GLHX and the supplemental devices are in parallel. Third, it cannot simulate other supplemental devices, such as solar thermal and radiant slab for snow melting, and so forth.

\section{New Wizard Screens in eQUEST 3.7}

The existing capabilities of the eQUEST Wizard for simulation of ground-loop heat pumps has been expanded to simulate 2-pipe fan coils coupled to a 2-pipe loop, served by a water-to-water heat pump and well field. The wizard accesses the water-to-water heat pump equipment added to the library. Because of the complexity of a water-to-water heat pump system, this implementation is restricted to the Wizard's "Design Development (DD) Wizard" mode only. In DD wizard screen 7, Fig. 4 shows that the chiller water and hot water coils are selected as cooling and heating sources, respectively. The system type is 2-pipe fan coils (chilled water or hot water). In the next screen as shown in Fig. 5, the chiller type is "chiller heat pump" and the condenser type is "ground loop." Fig. 6 shows the inputs for GroundSource HP Equipment-Loop Properties.

Fig. 4 Input in "2-Pipe Primary Equipment" screen

Fig. 5 Input in “2-Pipe Primary Equipment Chiller/Boiler” screen

Fig. 6 Input in "Ground-Source HP Equipment-Loop Properties" screen

Schematic design (SD) and design development (DD) wizards both were expanded to include wizards that quickly define the hybrid GHSP system. Here only the SD wizard is used to show the key wizard 
screens. As shown in Fig.7, DX coils and DX coils (heat pump) are the cooling and the heating sources in SD screen 19. The heat pump source is "ground loop." The cooling tower and/or the boiler can be selected with the GLHX in the SD wizard screen 30 as presented in Fig. 8. All the inputs associated with GLHX also can be defined in the same screen.

Fig. 7 Input in "HVAC System Definitions" screen

Fig. 8 Input in "Ground-Source HP Equipment-Loop Properties" screen

The selection of multi-year simulation can be done only in the detailed data edit mode. As shown Fig. 9, "sample year" is the default calculation algorithm when the number of prior years is non-zero. Although the user also can switch it to "all-years" method, the computation time will increase significantly.

Fig. 9 Options for multi-year simulation in detailed data edit mode

\section{Simulation of conventional and hybrid GSHP system in eQUEST 3.7}

Three different HVAC systems are compared including conventional GSHP, undersized GSHP, and HGSHP systems. The performance is analyzed in term of total HVAC energy consumption, as well as heat rejection and max/min entering fluid temperature. As shown in Fig. 10, a 2-story small office located in OKC was selected for this comparison study. The climate zone lies in Warm - Humid Climate zone $3 \mathrm{~A}$ as described in the ASHRAE standard 90.1-2010. Each floor of the office has a square footprint and total conditioned space of $1161 \mathrm{~m}^{2}$, including four thermal zones in the perimeter and one 
core zone in the interior, as illustrated in Fig. 11. The floor to floor height is $3.66 \mathrm{~m}$ with $0.91 \mathrm{~m}$ high return plenum. Table 3 lists the construction details of the small office building. The corresponding internal loads are shown in Table 4 including lighting power density, equipment load and occupant density.

Fig. 103D view of the simulated small office building

Fig. 11 Floor plan of the simulated small office building

Table 3 Construction of small office building

Table 4 Internal loads of small office building

The office operated from 8 am to 5 pm (Monday to Friday) and was closed on Saturday, Sunday and holiday. The HVAC system ran between 7 am and $6 \mathrm{pm}$. In the cooling mode, the thermostat setpoints were $24^{\circ} \mathrm{C}$ when occupied and $28^{\circ} \mathrm{C}$ when unoccupied. In the heating mode, $21^{\circ} \mathrm{C}$ was selected as occupied room temperature and $18^{\circ} \mathrm{C}$ was used in the unoccupied hours. The indoor fan was assumed to run continuously with the constant air flow rate during the occupied hours, and stay off when unoccupied. The fan efficiency and motor efficiency were 0.62 and 0.77 with $249 \mathrm{~Pa}$ pressure rise. Figs.12-13 show the daily building occupancy, lighting and equipment schedules.

Fig. 12 Building occupancy schedule 
Fig. 13 Building lighting schedule

Fig. 14 Building equipment schedule

As a key part of conventional and hybrid GSHP systems, the GLHX is used as a heat source and sink to cool or heat the condenser water. The sizing criterion is that the min EFT is above $7.2^{\circ} \mathrm{C}$ and the max EFT is below $35^{\circ} \mathrm{C}$ during the period of 30 year operation. It can limit the degradation of the performance heat pump in the heating and cooling seasons. The borehole depth is $76 \mathrm{~m}$ with a radius of $0.08 \mathrm{~m}$. The U-tube spacing and leg separation are $6 \mathrm{~m}$ and $0.1 \mathrm{~m}$. The pipe thermal conductivity is 0.4 W/m.K with inside and outside diameters of $0.022 \mathrm{~m}$ and $0.027 \mathrm{~m}$, respectively. The ground thermal conductivity and diffusivity are $2.9 \mathrm{~W} / \mathrm{m} . \mathrm{K}$ and $1.11 \times 10^{-6} \mathrm{~m}^{2} / \mathrm{s}$. The undisturbed ground temperature is $18^{\circ} \mathrm{C}$.

Case 1: For the conventional GSHP system, the GLHX is an 8x9 rectangular borehole field without the use of any supplemental heat rejection equipment. Basically, the system fully relies on the GLHX to meet the building heating and cooling loads.

Case 2: The undersized GSHP system has a smaller GLHX (4x8 rectangular borehole field) which is the same as the hybrid GSHP system. However, there is no supplemental heat rejection equipment included in the simulation. This case study is intended to illustrate a faster load aggregation and its effect on the entering fluid temperature to the heat pump. 
Case 3: The distributed HGSHP system has a 4x8 rectangular borehole field. The fluid cooler is attached to the same water loop with the GLHX. It is in series with the borehole field, and downstream of the borehole field. The GLHX will be preferentially loaded over the fluid cooler. However, if the GLHX is counterproductive (i.e., warming the water when heat pumps are in cooling mode), and a fluid cooler is also enabled, then the GLHX will be bypassed (to save pump energy) and the fluid cooler used exclusively. The fluid cooler will also be enabled when the EFT from the GLHX is higher than the cooling setpoint. When enabled, the fluid cooler will modulate a one-speed cycling fan to maintain the cooling temperature set-point. When the fluid cooler is disabled, the flow will bypass the fluid cooler. The fixed temperature control was chosen for HGSHP system. The loop cooling setpoint is $84 \mathrm{~F}$.

As presented in Table 5, the simulation result shows that the total HVAC energy consumption of the conventional GSHP is 67,983 kwh which is the lowest as compared with other two systems. The undersized GSHP and distributed hybrid GSHP systems are very close to each other, slightly less than $5 \%$ difference, with about $60 \%$ smaller GLHX.

The conventional GSHP consumes about $12 \%$ and $17 \%$ less electric for space cooling than other two systems, respectively, because the larger GLHX can provide a cooler entering fluid temperature to the heat pump and improve compressor efficiency in the cooling mode. Because the HGSHP system rejects the heat through both GLHX and fluid cooler, its EFT is lower than that of the undersized GSHP system. So, it has less space-cooling energy end use, but consumes additional $1764 \mathrm{kwh}$ electricity to run the fluid cooler. Also, the HGSHP system needs to overcome the pressure drop through the GLHX and fluid cooler. As a result, its loop pump consumes more energy than those of conventional and undersized GSHP systems. For space heating and ventilation fans, all three systems have roughly the same energy end uses. 


\section{Table 5 HVAC electric consumptions (kwh) in year 1}

Besides the annual HVAC energy consumption, the entering fluid temperature to the heat pump is also another key parameter that affects heat pump performance. Table 6 summarizes fluid cooler rejection loads, GLHX heating/cooling loads, and max/min entering fluid temperatures to the heat pump for three HVAC system types in year 1 and year 30. On an annual basis, the heat rejection to the ground is much higher than the heat extraction from the ground. So, even with a supplementary heat rejecter like the fluid cooler, the heat still builds up in the ground. The increment of the max and min EFTs proves the load aggregation in the ground during the 30 year operation.

In year 30, the conventional GSHP systems reject more heat than in year 1 because the compressor consumes more electricity to provide the same cooling output to condition the spaces due to the higher EFT to heat pump. In year 1 , the EFT fluctuates between $78.5^{\circ} \mathrm{F}$ and $56.9^{\circ} \mathrm{F}$. The max and min EFTs increase about $12.7^{\circ} \mathrm{F}$ in year 30 .

A 30 year simulation predicts that the undersized GSHP system has the highest temperature rise. Even for the first year, the max EFT to heat pump already exceeds $100^{\circ} \mathrm{F}$. In year 30 , the max EFT is over $120^{\circ} \mathrm{F}$. The temperature range is significantly wider than that of conventional and HGSHP systems. This indicates that the same amount of heat can't be dissipated through the shorter loop length. Without the supplemental heat rejecter, the quick load aggregation can cause the higher EFT to heat pump and degrade the efficiency of the compressor in cooling mode over time. 
For HGSHP system, the GLHX rejects less heat in year 30 than the amount of the heat rejected in year 1 due to the temperature rise in the ground. Accordingly, the fluid cooler runs somewhat longer to main the cooling setpoint by rejecting more heat to the air. Basically, the heat rejection load just shifts from the GLHX to the fluid cooler. The increment of the max EFT is only $2.4^{\circ} \mathrm{F}$. Therefore, heat build-up in the ground can be mitigated with a properly designed HGSHP system.

\section{Table 6 Heat rejections by GLHX/fluid cooler and max/min EFTs in year 1 and year 30}

\section{Conclusion}

The new enhancements were incorporated into eQUEST 3.7/DOE-2.3. The ground-coupled, water-towater heat pump system was successfully added as an alternative configuration of the GSHP system. Rather than using an approximate loading history generated with a sinusoidal loading function between peak heating and cooling loads, the program now allows for either full multi-year simulations, or simulation of previous years using a weighted sample of the years. The program also can simulate a GLHX together with the supplemental heat rejection device and/or boiler to reduce the size of the well field. The eQUEST graphical user interface was modified to include these enhancements and released as eQUEST-3.70.

\section{Acknowledgement}

This work is based upon work supported by the U. S. Department of Energy under Award No. DEEE002799. 


\section{References}

[1] Claesson, J., Eskilson, P., Simulation Model for Thermally Interacting Heat Extraction Boreholes, Lund University, Sweden, 1987.

[2] Claesson, J., Eskilson, P., "Conductive Heat Extraction by a Deep Borehole”, Lund University, Sweden, 1987.

[3] Eskilson, P., Thermal Analysis of Heat Extraction Boreholes. Doctoral Thesis, 1987. University of Lund, Department of Mathematical Physics. Lund, Sweden.

[4] Claesson J, Eftring B, Hellström G and P Olanders, Theoretical analysis and computer simulation of solid-fluid heat storage systems in the ground, 1978.

[5] Yavuzturk, C., J.D. Spitler, and S.J. Rees. A transient two-dimensional finite volume model for the simulation of vertical U-tube ground heat exchangers. ASHRAE Transactions 105(2): 465-474, 1999.

[6] DOE-2.2 Volume 2: Dictionary, June 2006.

[7] DOE-2.3 Volume 6: New features, February 2014.

[8] DOE-2.3 Volume 2: Dictionary, February 2014. 


\section{TABLE CAPTIONS}

Table 1 Water-Air heat pump capacity and EIR performance curves

Table 2 Water-to-Water heat pump capacity and EIR performance curves

Table 3 Construction of small office building

Table 4 Internal loads of small office building

Table 5 HVAC electric consumptions (kWh) in Year 1

Table 6 Heat rejections by GLHX/fluid cooler and EFT rise in year 1 and year 30 
Table 1 Water-Air heat pump capacity and EIR performance curves

\begin{tabular}{|l|l|l|}
\hline \multicolumn{1}{|c|}{ Performance curve } & \multicolumn{1}{c|}{ Cooling mode } & \multicolumn{1}{c|}{ Heating mode } \\
\hline Capacity correction factor & $\mathrm{a}+\mathrm{b} \times \mathrm{EWBT}+\mathrm{c} \times \mathrm{EFT}$ & $\mathrm{a}+\mathrm{b} \times \mathrm{EDBT}+\mathrm{c} \times \mathrm{EFT}$ \\
\hline EIR correction factor & $\mathrm{a}+\mathrm{b} \times \mathrm{EWBT}+\mathrm{c} \times \mathrm{EFT}$ & $\mathrm{a}+\mathrm{b} \times \mathrm{EDBT}+\mathrm{c} \times \mathrm{EFT}$ \\
\hline EIR correction factor & $\mathrm{a}+\mathrm{b} \times \mathrm{PLR}+\mathrm{c} \times \mathrm{PLR}^{2}$ & $\mathrm{a}+\mathrm{b} \times \mathrm{PLR}+\mathrm{c} \times \mathrm{PLR}^{2}$ \\
\hline
\end{tabular}

Table 2 Water-to-Water heat pump capacity and EIR performance curves

\begin{tabular}{|c|c|c|}
\hline Performance curve & Cooling mode & Heating mode \\
\hline Capacity correction factor & $\begin{array}{l}\mathrm{a}+\mathrm{b} \times \mathrm{CHW}+\mathrm{c} \times \mathrm{CHW}^{2}+ \\
\mathrm{d} \times \mathrm{EFT}+\mathrm{e} \times \mathrm{EFT}^{2} \mathrm{f} \times \mathrm{CHW} \times \mathrm{EFT}^{2}\end{array}$ & $\begin{array}{l}\mathrm{a}+\mathrm{b} \times \mathrm{HW}+\mathrm{c} \times \mathrm{HW}^{2}+ \\
\mathrm{d} \times \mathrm{EFT}+\mathrm{e} \times \mathrm{EFT}^{2} \mathrm{f} \times \mathrm{HW} \times \mathrm{EFT}^{2}\end{array}$ \\
\hline EIR correction factor & $\begin{array}{l}\mathrm{a}+\mathrm{b} \times \mathrm{CHW}+\mathrm{c} \times \mathrm{CHW}^{2}+ \\
\mathrm{d} \times \mathrm{EFT}+\mathrm{e} \times \mathrm{EFT}^{2} \mathrm{f} \times \mathrm{CHW} \times \mathrm{EFT}^{2}\end{array}$ & $\begin{array}{l}\mathrm{a}+\mathrm{b} \times \mathrm{HW}+\mathrm{c} \times \mathrm{HW}^{2}+ \\
\mathrm{d} \times \mathrm{EFT}+\mathrm{e} \times \mathrm{EFT}^{2} \mathrm{f} \times \mathrm{HW} \times \mathrm{EFT}^{2}\end{array}$ \\
\hline
\end{tabular}

Table 3 Construction of small office building 


\begin{tabular}{|c|c|}
\hline Exterior wall & $\begin{array}{r}\text { Metal frame, 2x6, 24 in o.c. with plywood, 3/4 in fiber board } \\
\text { sheathing (R-2) and R-19 batt insulation }\end{array}$ \\
\hline Roof & $\begin{array}{r}\text { Metal frame, >24 in. o.c. built-up roof with R-18 } \\
3 \text { in. polyurethane insulation }\end{array}$ \\
\hline Floor & Slab-on-grade with 6 in concrete and vinyl tile \\
\hline Windows & 1) Double pane clear,1/2 in glass, 1/2 in air gap \\
& 2) Double pane clear,1/2 in glass, 1/4 in air gap \\
\hline Door & Single clear/tint \\
\hline
\end{tabular}

Table 4 Internal loads of the small office building

\begin{tabular}{|c|c|}
\hline Internal Load & Unit \\
\hline Light power density & $14.2 \mathrm{w} / \mathrm{m}^{2}$ \\
\hline Equipment load & $6.1 \mathrm{w} / \mathrm{m}^{2}$ \\
\hline Occupant density & 6 people $/ 100 \mathrm{~m}^{2}$ \\
\hline
\end{tabular}

Table 5 HVAC electric consumptions (kwh) in year 1

\begin{tabular}{|l|ll|ll|ll|}
\hline Case No. & Conventional & GSHP & Undersized & GSHP & Distributed HGSHP \\
\hline
\end{tabular}




\begin{tabular}{|c|c|c|c|}
\hline & \multicolumn{2}{|l|}{$(8 \times 9)$} & $(4 \times 8)$ \\
\hline Space Cool & 26766 & 32329 & 30463 \\
\hline Tower Fan & 0 & 0 & 166 \\
\hline Spray Pump & 0 & 0 & 1598 \\
\hline Space Heat & 4005 & 4119 & 4121 \\
\hline Vent. Fans & 23582 & 23582 & 15622 \\
\hline Loop Pump & 13630 & 13672 & 75552 \\
\hline HVAC Total & 67983 & 73702 & \\
\hline
\end{tabular}

Table 6 Heat rejections by GLHX/fluid cooler and max/min EFTs in year 1 and year 30

\begin{tabular}{|c|c|c|c|c|c|c|}
\hline Case No. & Year & $\begin{array}{c}\text { Fluid cooler Heat } \\
\text { Rejection Load } \\
(\mathrm{MWH})\end{array}$ & $\begin{array}{c}\text { GLHX Cool Load } \\
(\mathrm{MWH})\end{array}$ & $\begin{array}{c}\text { GLHX Heat Load } \\
(\mathrm{MWH})\end{array}$ & Max EFT $\left({ }^{\circ} \mathrm{C}\right)$ & Min EFT $\left({ }^{\circ} \mathrm{C}\right)$ \\
\hline \multirow{2}{*}{ GSHP (8x9) } & Year 1 & 0 & 228 & -16 & 25.8 & 13.8 \\
\cline { 2 - 7 } & Year 30 & 0 & 233 & -17 & 32.9 & 21.0 \\
\hline GSHP (4x8) & Year 1 & 0 & 233 & -16 & 49.2 & 16.2 \\
\cline { 2 - 7 } & Year 30 & 0 & 240 & -17 & 30.6 & 7.2 \\
\hline Distributed & Year 1 & 30 & 203 & -16 & 31.9 & 12.8 \\
\cline { 2 - 7 }
\end{tabular}




\section{FIGURE CAPTIONS}

Fig. 1 Heat rejection loads for hybrid GSHP system

Fig. 2 Schematic of hybrid GSHP system

Fig. 3 Schematic of Central HGSHP System

Fig. 4 Input in "2-Pipe Primary Equipment" screen

Fig. 5 Input in "2-Pipe Primary Equipment Chiller/Boiler” screen

Fig. 6 Input in "Ground-Source HP Equipment-Loop Properties" screen

Fig. 7 Input in "HVAC System Definitions" screen

Fig. 8 Input in "Ground-Source HP Equipment-Loop Properties" screen

Fig. 9 Options for multi-year simulation in detailed data edit mode

Fig. 103D view of the simulated small office building

Fig. 11 Floor plan of the simulated small office building

Fig. 12 Building occupancy schedule

Fig. 13 Building lighting schedule

Fig. 14 Building equipment schedule 
Click here to download high resolution image

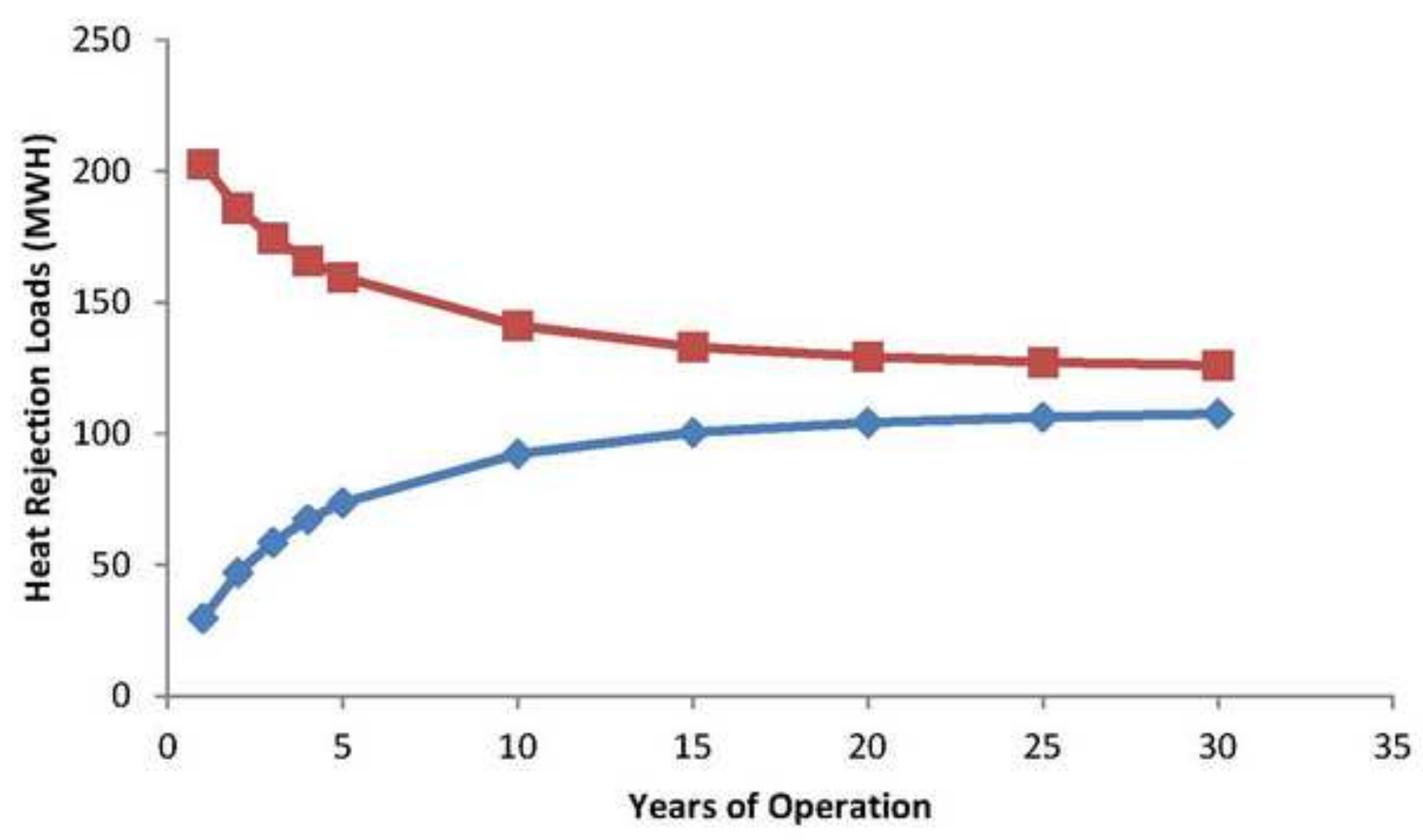

$\sim$ Fluid Cooler $\quad-$ GLHX 
A cooling tower and/or a boiler in series and downstream of GLHX

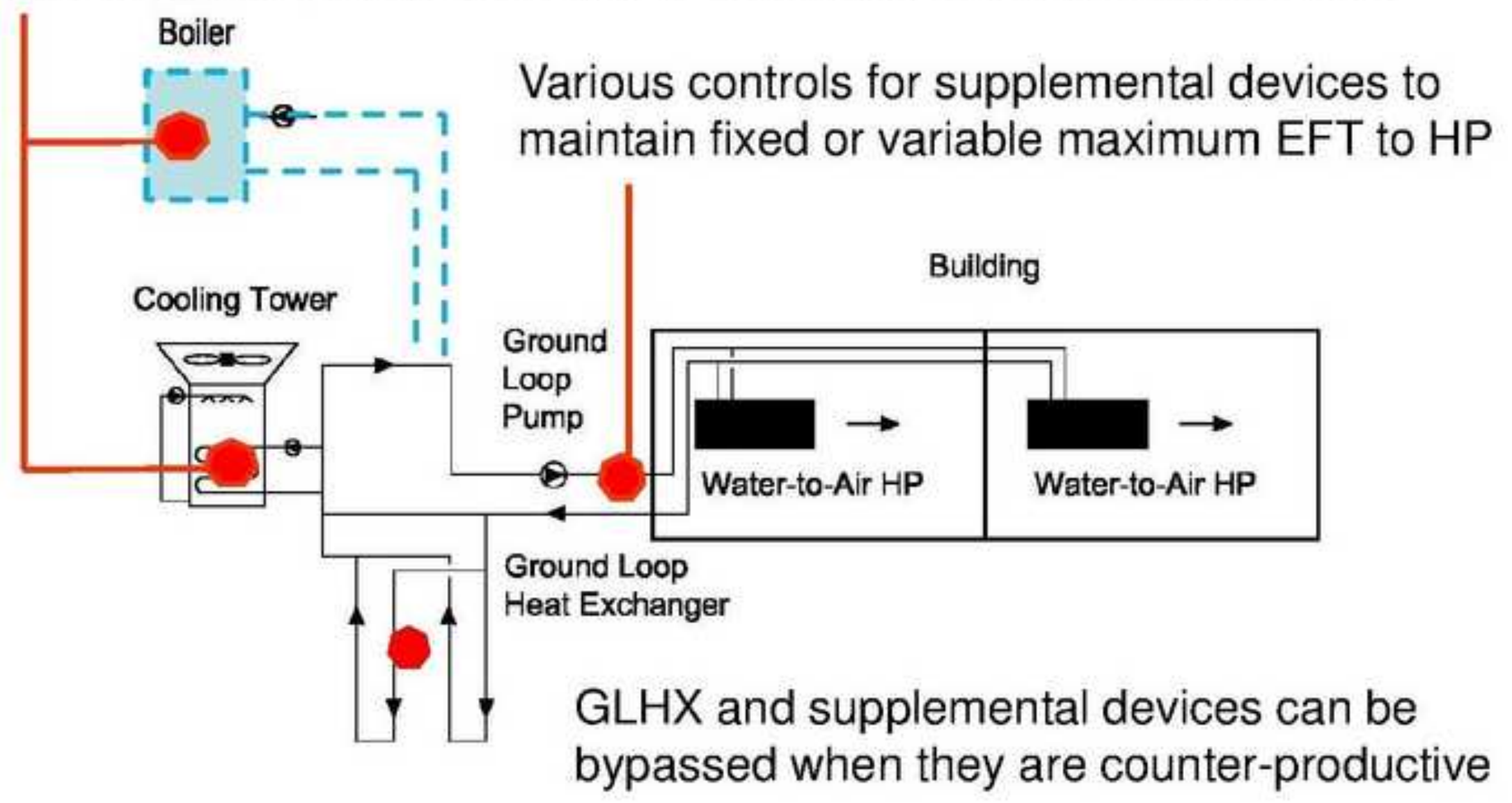




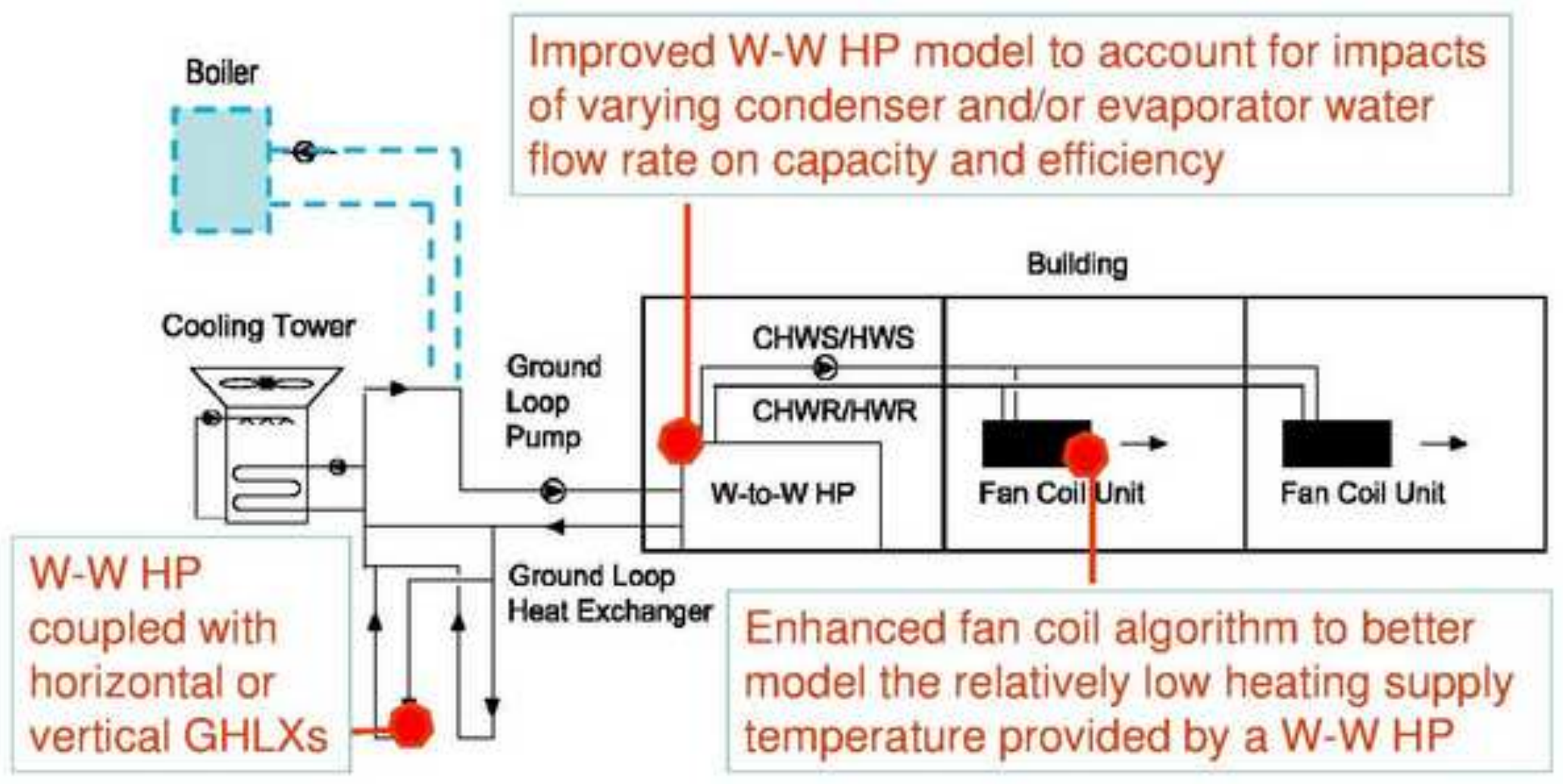




\section{X eQUEST DD Wizard: Air-Side System Type -- HWAC System 1}

\section{HYaC System Definition}

$\begin{array}{rll}\text { System Type Name: } & \text { HVAC System } 1 \\ \text { Cooling Source: } & \text { Chilled Water Coils } \\ \text { Heating Source: } & \text { Hot Water Coils } \\ \text { System Type: } & \text { 2-Pipe Fan Coils (CHW' or HW') } \\ \text { System per Area: } & \text { System per Shell }\end{array}$

Component Name Prefix: $\$ 1$

Suffix:

(\# Prefix + Suffix characters must be $<=4$ )

Prevent duplicate model components

System Assignment to Thermal Zones*

\begin{tabular}{|l|l|l|l|}
\hline \multicolumn{1}{|c|}{ Shell Component(s) } & \multicolumn{2}{c|}{ Description of Assigned Zones } \\
\hline 1 & Bldg Envelope \& Loads 1 & - & All Zones \\
\hline 2 & - undefined - & \\
\hline
\end{tabular}

* Assignments here are superseded by HVAC assignments made on the zone group screen (by shell) 
Click here to download high resolution image

\section{CX eQUEST DD Wizard: 2-Pipe Plant Equipment}

\section{2-Pipe Primary Equipment Chiller/Boiler}

Chiller 1

Chiller Type:

Condenser Type:

\begin{tabular}{|l|}
\hline Chiller Heat Pump \\
\hline Ground Loop
\end{tabular}

Chiller Counts \& Sizes:

Chiller Efficiency:

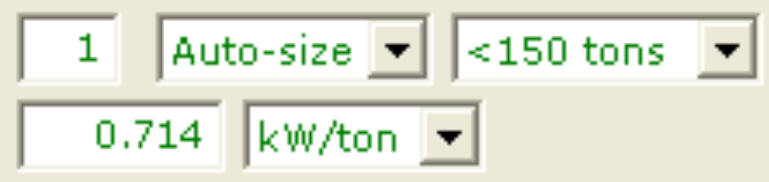

wizard Screen 


\section{C eQUEST DD Wizard: GSHP Plant Equipment}

\section{Ground-Source HP Equipment - Loop Properties}

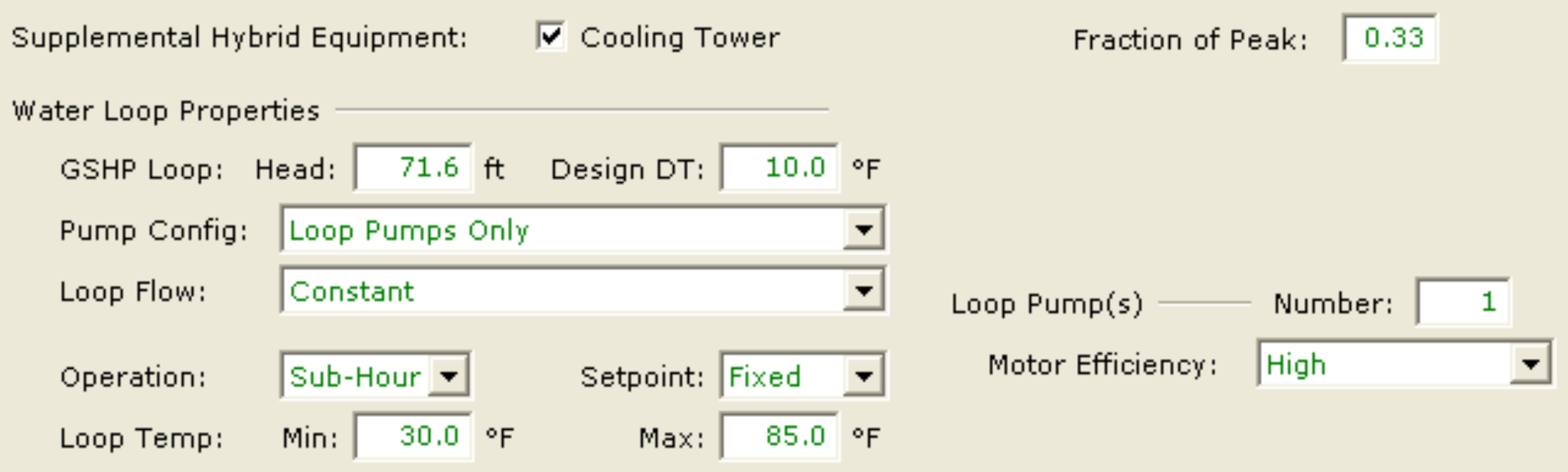




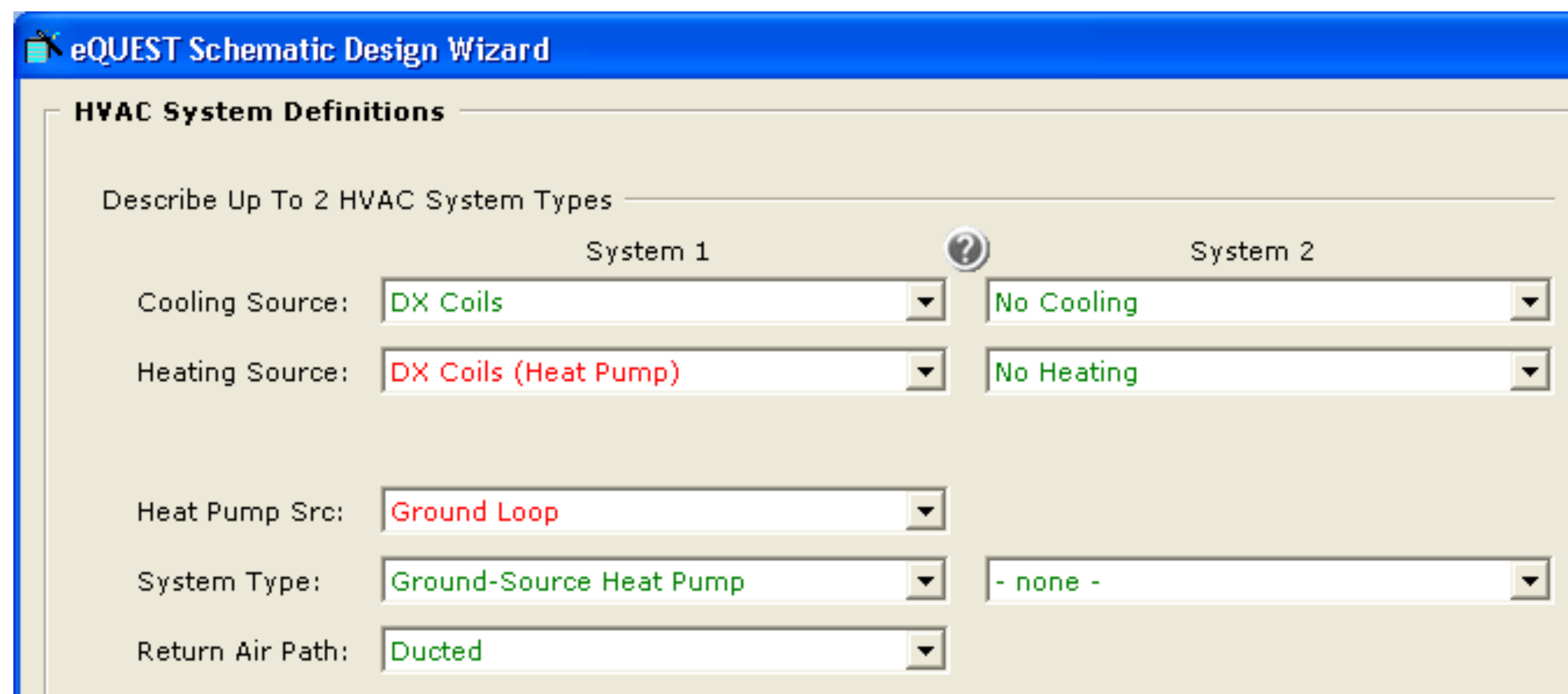

wizard Screen 19 of 41

(?) Help 


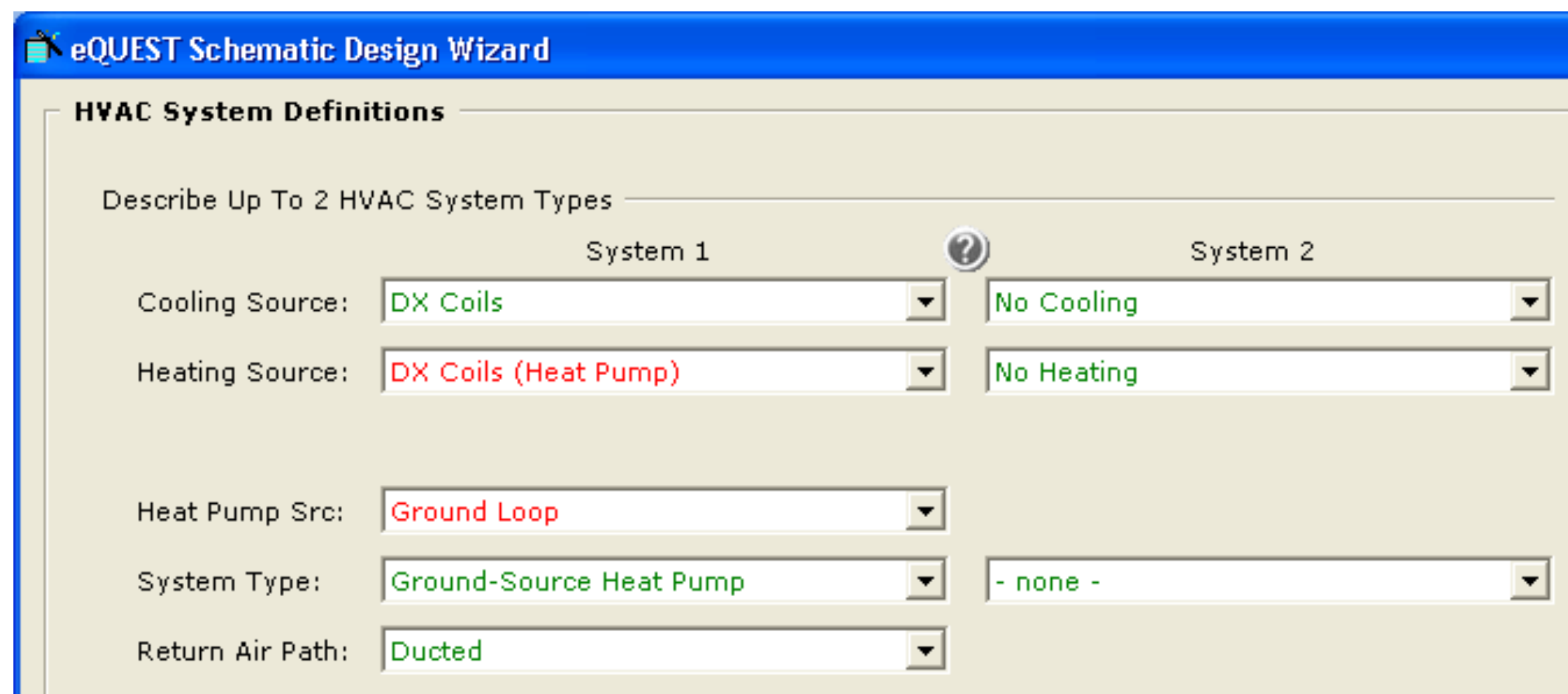

wizard Screen 19 of 41

(?) Help 
Click here to download high resolution image

\section{Ground Loop Heat Exchanger Properties}

Currently Active Ground HX: GLHX (VertWell-CM)

Type: Vertical Wells - G-Functions

\section{Basic Specifications Ground Properties Attachments}

Soil Thermal Properties \& History Undisturbed Avg Ground Temp: Undisturbed Ground Adjustment:

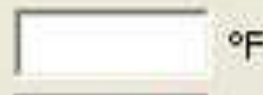

Ground Thermal Diffusivity: $5.0 \circ$ \% (delta)

Ground Thermal Conductivity: Years of Previous Operation: History Simulation Years:

\begin{tabular}{|c|c|c|}
\hline 0.043 & $\mathrm{ft} 2 / \mathrm{hr}$ & \\
\hline 1.680 & Btujh-ft & \\
\hline 29 & & \\
\hline Sample Y & ears & $\boldsymbol{\nabla}$ \\
\hline - undefine & $d=$ & \\
\hline $\begin{array}{l}\text { Sample Y } \\
\text { All Years }\end{array}$ & & \\
\hline
\end{tabular}


Figure(s)

Click here to download high resolution image

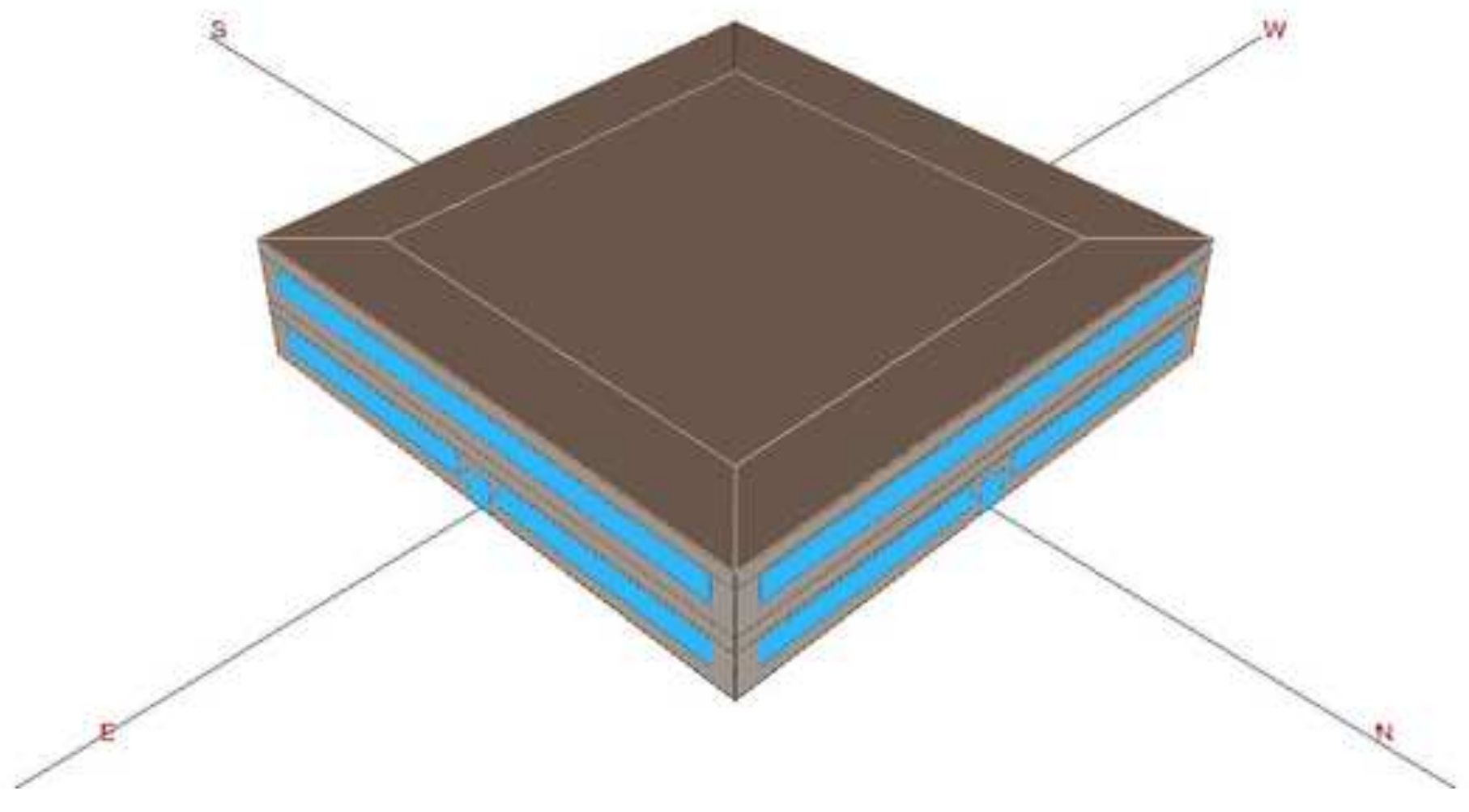




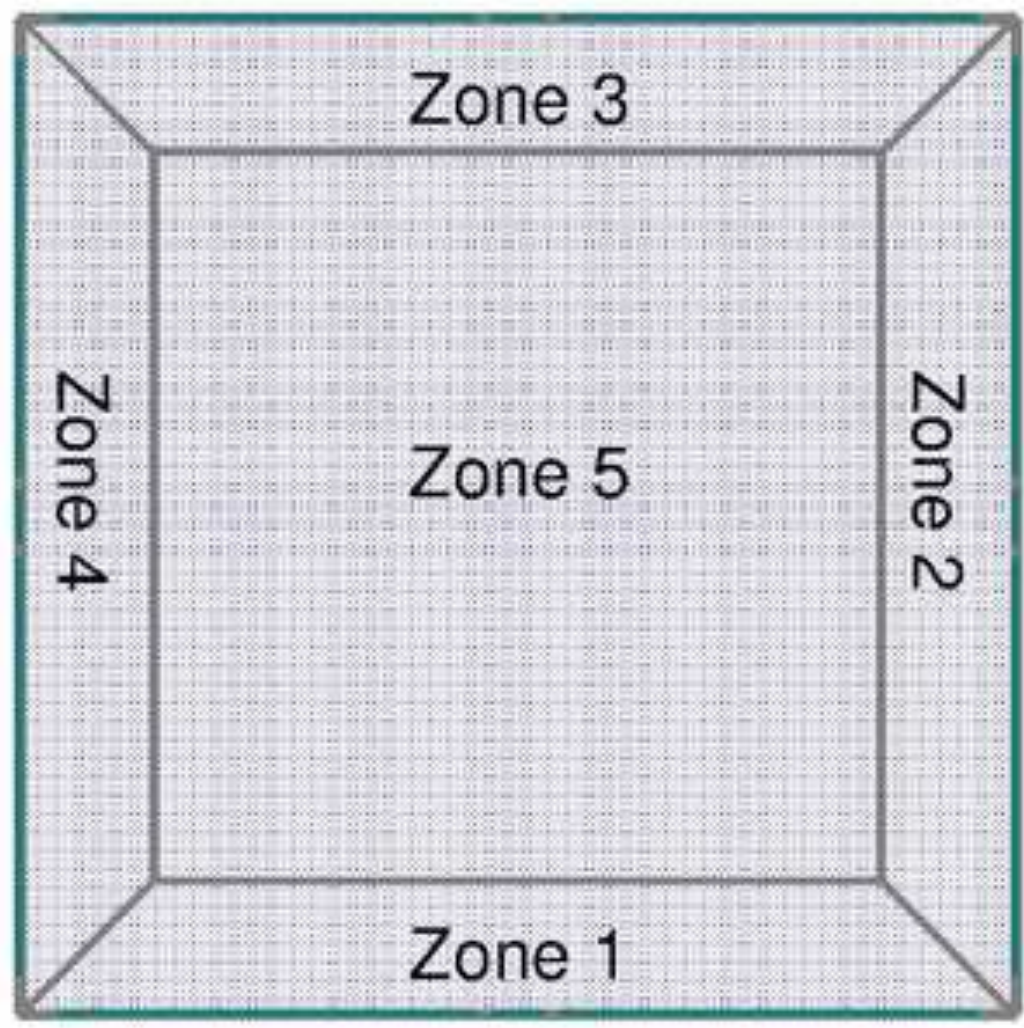




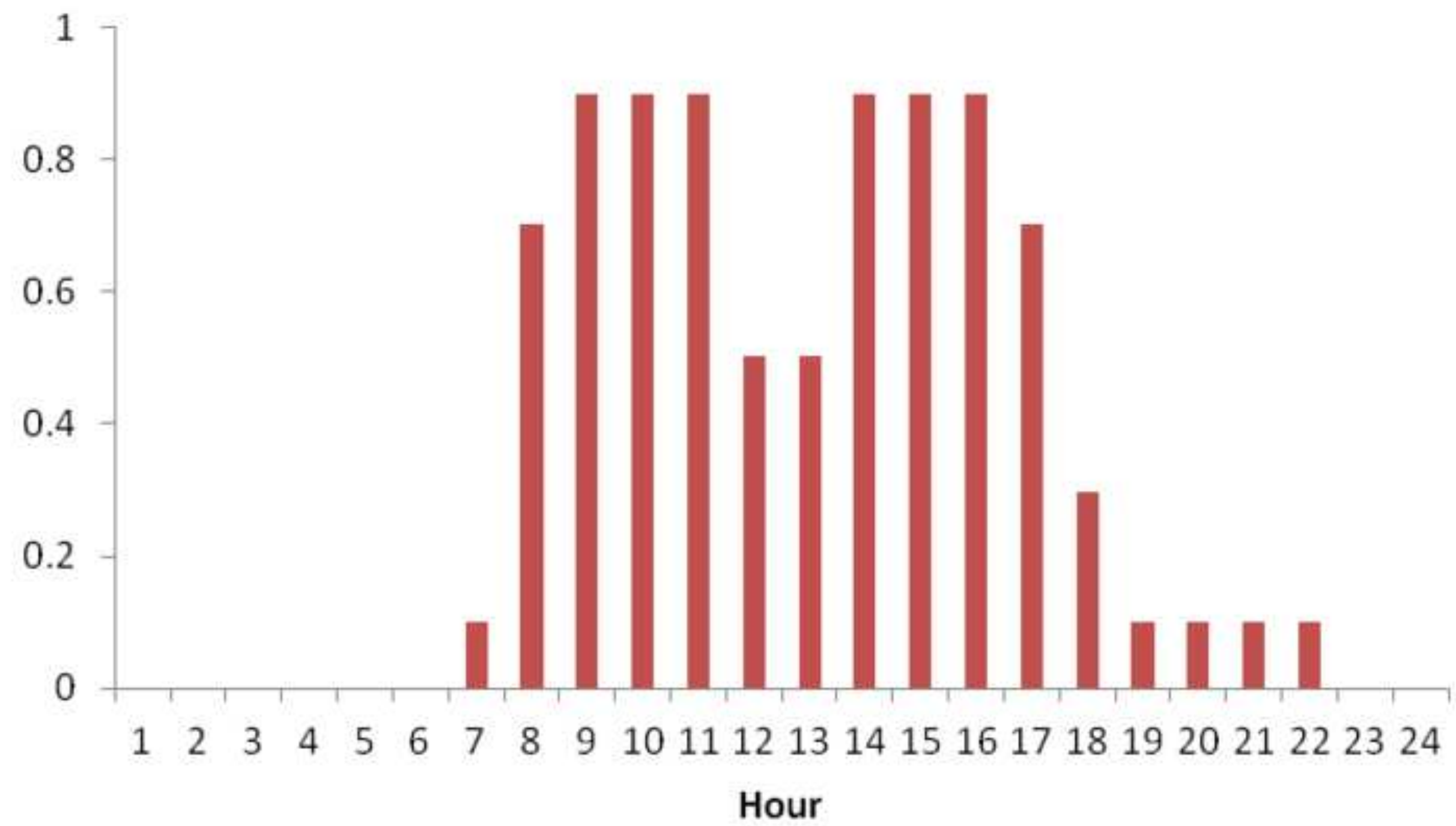




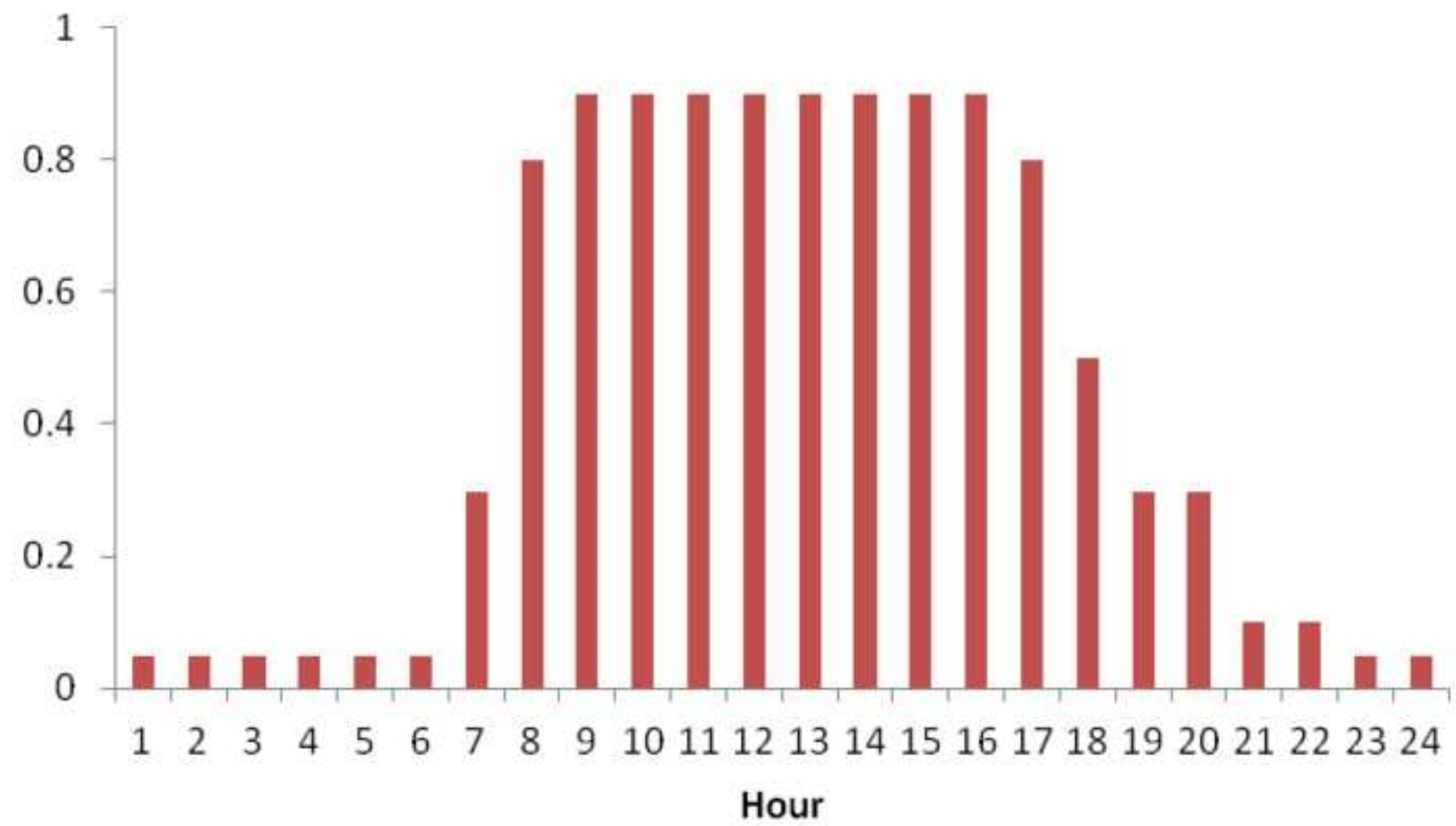




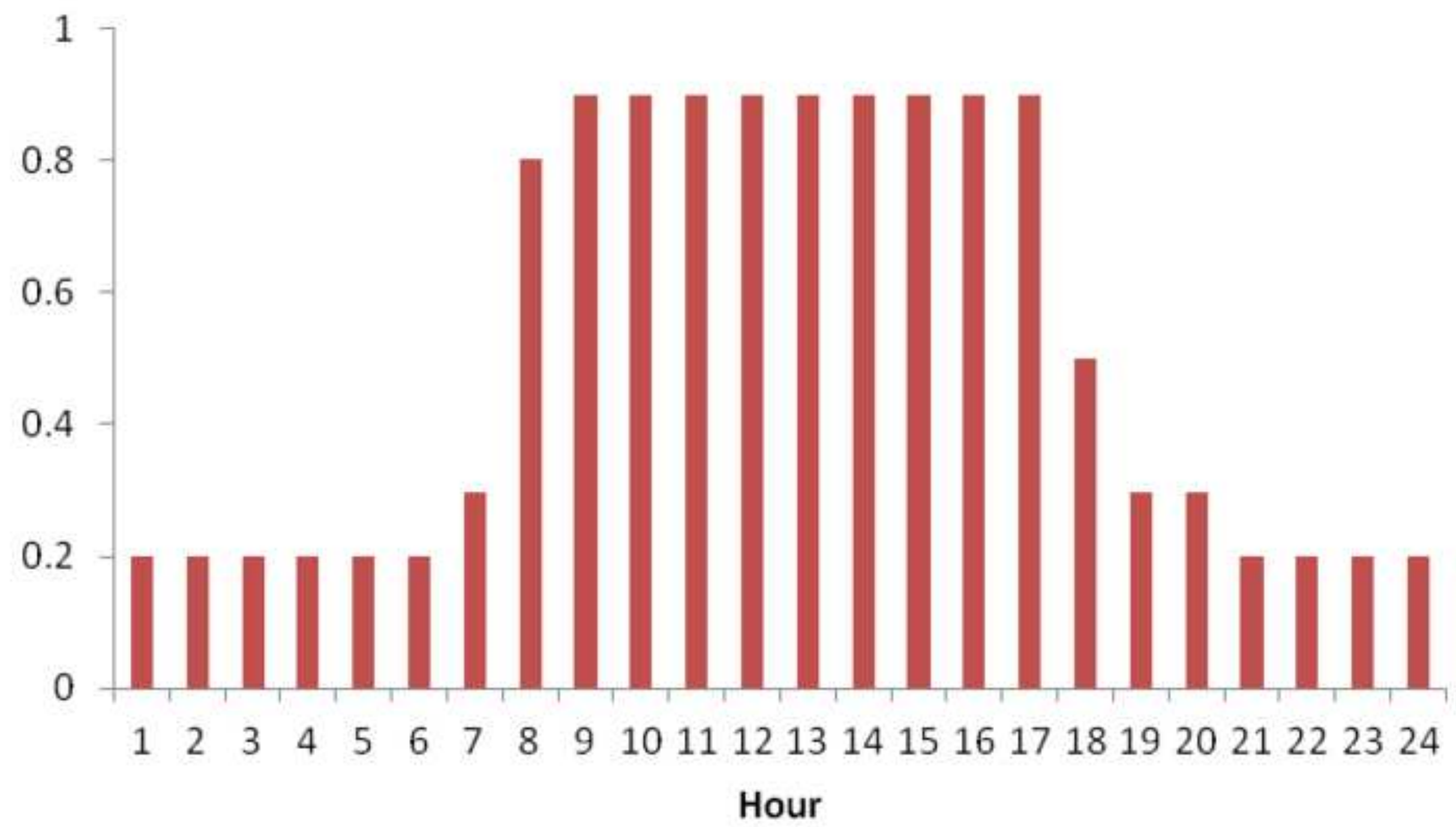

